Article

\title{
The Advantages of Landsat 8-OLI-Derived Suspended Particulate Matter Maps for Monitoring the Subtidal Extension of Amazonian Coastal Mud Banks (French Guiana)
}

\author{
Noelia Abascal Zorrilla ${ }^{1, *}$, Vincent Vantrepotte ${ }^{1,2}$, Erwan Gensac ${ }^{3}$, Nicolas Huybrechts 4,5 \\ and Antoine Gardel ${ }^{1}$ \\ 1 Centre National de La Recherche Scientifique-CNRS, USR3456, 97334 Cayenne, French Guiana, France; \\ vincent.vantrepotte@univ-littoral.fr (V.V.); antoine.gardel@univ-littoral.fr (A.G.) \\ 2 Laboratoire d'Océanologie et de Géosciences, Université du Littoral-Côte-d'Opale, CNRS, Université de \\ Lille, 32 Avenue Foch, 62930 Wimereux, France \\ 3 Laboratoire Géosciences Océan UMR 6538, Université Bretagne Sud, rue André Lwoff, 56000 Vannes, France; \\ erwan.gensac@univ-ubs.fr \\ 4 Cerema Eau Mer Fleuve, 134 rue de Beauvais, 60280 Margny Les Compiègne, France; \\ nicolas.huybrechts@cerema.fr \\ 5 Sorbonne Université, Laboratoire Roberval-FRE UTC—CNRS 2012, Université de Technologie de \\ Compiègne, Centre de Recherche de Royallieu CS 60319, 60203 Compiègne, France \\ * Correspondance: noelia.abascal-zorrilla@cnrs.fr
}

Received: 31 August 2018; Accepted: 1 November 2018; Published: 3 November 2018

\begin{abstract}
The coast of French Guiana is characterised by the northwestward migration of large mud banks alongshore and by high concentrations of suspended particulate matter (SPM) resulting from the strong influence of the Amazon River outflow. Surface OLI SPM concentration, linked to the footprint of the subtidal part of mud banks due to resuspension and migration processes, was used to develop a method to estimate the location of this footprint. A comparison of the results from this method with those obtained by locating the limit of the wave damping, which characterises muddy coasts, revealed good performance of the method based on recurring SPM values. The migration rates of the mud banks in French Guiana were calculated according to the delimitation of their subtidal parts, and showed slightly higher values $(2.31 \mathrm{~km} /$ year $)$ than suggested by earlier studies. In comparison with other methods, the migration rate estimated using the method proposed within the framework of this study takes into account the variability of the shape of the subtidal part for the first time. It was also shown that the mud banks existing on the coastal area of French Guiana present two different shapes. Our results clearly demonstrate the advantage of ocean colour data to describe mud banks according to their subtidal part, delimited using the assessment of SPM temporal variability.
\end{abstract}

Keywords: Keywords: suspended matter; mud banks; ocean colour; Landsat 8; French Guiana

\section{Introduction}

As is the case along the $1500 \mathrm{~km}$ long coast between the mouths of the Amazon and Orinoco Rivers, the coastal waters of French Guiana are strongly impacted by the mud supply from the Amazon [1]. About $15-20 \%$ of this muddy discharge, estimated at $8.108 \mathrm{t}$ /year by Martinez et al. [2], migrates north-westward. Controlled by waves and currents, mud banks are subsequently formed and migrate alongshore the coast of French Guiana, Suriname, and Guyana [3-7]. In any year, there may be 15 or more actively-translating mud banks between the Amazon and the Orinoco. They are spaced out 15-25 km apart (interbank areas), migrate at velocities ranging from 1 to $5 \mathrm{~km} / \mathrm{yr}$, and are $5 \mathrm{~m}$ thick, 10 
to $60 \mathrm{~km}$ long, and 20 to $30 \mathrm{~km}$ wide [6,8]. However, their subtidal extension has still not been clearly defined. Transport on the inner shelf of these migrating mud banks has been mainly attributed to wind waves [9]. These waves interact with the subtidal part of the mud bank, composed of soft to fluid mud, at spatial and temporal scales defined by wavelength and period. In the case of seafloors characterised by fluidized mud, the bed moves and results in a dampening of incoming waves by the fluid mud layer, thus leading to the creation of an intertidal mud flat. Several studies have been carried out on wave energy dissipation in the world's muddy areas; for example, mud banks on the shore of the Surinam and Guyana coasts are estimated to account for 88\% to 96\% wave energy dissipation [10-12].

The alongshore migration of mud banks has considerable coastal ecological (development and destruction of mangroves, role of mangroves as a nursery ground) and economic (harbour silting, navigation problems entailing daily dredging, erosion of arable land) impacts on all the countries of this 1500-km-long muddy coast. Amazonian mud banks have been extensively studied [3,5,8,9,12-15]. The back of the bank, generally colonized by seafront mangroves (Avicennia germinans), composed of consolidated mud ( $\geq 750 \mathrm{~g} / \mathrm{L} \mathrm{[9],} \mathrm{and} \mathrm{not} \mathrm{protected} \mathrm{by} \mathrm{subtidal} \mathrm{soft} \mathrm{mud,} \mathrm{is} \mathrm{eroded} \mathrm{and} \mathrm{fluidized}$ essentially through the action of waves, as well as, to a lesser degree, the influence of tides and wind-induced geostrophic currents [15]. The particulate matter thus mobilized is then transported to the leading edge of the bank, resulting in a displacement of the mud bank along the coastline following the direction of the longshore drift, which is oriented northwestward (e.g., [16,17]). Although several studies have been carried out, several uncertainties exist on the processes driving mud bank formation and migration [1]. Monitoring the subtidal extension of mud banks and understanding the hydro-sedimentary processes linked to their migration could help resolve unanswered questions.

Satellite data have been used effectively for monitoring surface-suspended particulate matter (SPM) [18-22], and have revealed a strong spatio-temporal coupling with mud banks. Recent studies have allowed a better characterization of the morphodynamics of French Guiana mud banks from remote sensing $[14,20,22]$. These previous studies were based on high- (SPOT and Landsat) and medium-resolution sensors (MODIS). Despite the high temporal resolution of medium-resolution sensors, which enables a good overview of mud bank dynamics, the details of the subtidal footprint of mud banks in the near coastal waters are lacking. By contrast, SPOT and Landsat studies have made a qualitative study of mud banks possible, providing information about mud bank migration, for example. Recently-launched high-resolution sensors, such as Sentinel 2 (10-60 m every 5 days) and Landsat 8 (15-30 m every 16 days), compensate for the spatial limitation, and significantly improve the study of the small-scale spatial variability of these waters. This makes the quantitative study of mud bank features possible via SPM estimation, as it provides relevant insight for the assessment and monitoring of mud banks. Several algorithms have been developed for estimating SPM for a variety of ocean colour sensors [23-29], based on the strong positive correlation existing between the marine reflectance in the red-near infrared (NIR) bands or different band ratios and the amount of particulate matter present in the water body. Due to the high turbidity of the waters between the Amazon and Orinoco rivers, efforts have been made to develop regional algorithms for medium-resolution sensors [21,22,30], providing SPM estimates with satisfactory accuracy.

The objective of this work is to demonstrate the potential of high-resolution sensors to estimate the location of the subtidal part of mud banks and study their migration, since SPM concentration is related to the footprint of the subtidal part of mud banks due to resuspension and migration processes. A method based on SPM spatio-temporal variability is developed to detect the footprint of mud banks via Landsat-8 OLI imagery. The wave damping limits observed off French Guiana's coast [9], visible via Landsat 8 panchromatic band, are compared with the limits obtained using the SPM-based method in order to evaluate the consistency between these two independent approaches which are based on different underlying physical processes. 


\section{Materials and Methods}

\subsection{In Situ Measurements}

\subsubsection{Wave Measurements}

Two pressure sensors (SP2TCNKE) configured with a $4 \mathrm{~Hz}$ recording frequency were installed on the sea bottom opposite the city of Cayenne on 21 November 2017 for six hours. The first one was deployed at a water depth of $2 \mathrm{~m}$ on the subtidal part of the mud bank, and the second at a water depth of $5 \mathrm{~m}$ facing the mud bank. Significant wave heights were calculated by an FFT analysis of the pressure signal on 20-min-long bursts [31].

\subsubsection{Seismic Profile}

Seismic data make it possible to see through the sea bottom, revealing details of the sediment architecture, such as thickness. In this work, seismic profiles helped to pinpoint mud banks via the sound wave and its two way time (TWT-two-way travel time to depth). The method used consists of the detection of the deformation caused by waves on the profile; if deformation exists, the mud bank is not located at that point of the profile. The seismic device used was an Edgetech Full Spectrum Sub Bottom (Chirp technology) with a frequency range of about 4 to $24 \mathrm{kHz}$, paired with a GPS system. The vertical resolution is less than $8 \mathrm{~cm}$, and the vertical penetration in a muddy environment is about 40 m. Data were analysed with Kogeo@ software version 2.7 (http:/ / www.kogeo.de/index.htm).

\subsection{Satellite Data}

\section{Landsat 8-OLI data}

The images used within the framework of this study were collected by Landsat 8 . The OLI sensor has eight bands. The first four are in the visible, band 5 is in the near infrared (NIR), and bands 6 and 7 are in the shortwave infrared spectral regions (SWIR); all seven have a spatial resolution of $30 \mathrm{~m}$. In addition, there is a panchromatic band with a resolution of $15 \mathrm{~m}$. The revisit time of Landsat 8-OLI is 16 days.

OLI level 1 data (L1T) were downloaded from the Earth Explorer data base (https: / / earthexplorer. usgs.gov /) for the four scenes covering the study area between April 2013 and December 2017, leading to a total of 151 Landsat 8-OLI images after the elimination of images that were highly affected by clouds.

The low latitude of French Guiana $\left(3^{\circ} 30-6^{\circ} 30 \mathrm{~N}\right)$ and the solar and viewing path geometry of OLI led to the presence of a quasi-permanent glint contamination over the Landsat 8-OLI images used within the framework of this study. As a consequence, the use of Landsat 8-OLI data is highly limited due to the loss of the pixels located towards the eastern part of the four scenes covering this coastal domain [32]. In this study, a historical method based on the use of NIR information for estimating the level of sun glint was applied in order to correct for this effect [33], taking advantage of the availability of SWIR information which is more adapted for applications related to very turbid waters such as those of French Guiana [32].

Landsat 8 L1T sun glint-corrected data were processed using ACOLITE software (acolite_win 20170718.0) developed at RBINS (https: / / odnature.naturalsciences.be/remsem/software-and-data/ acolite). The ACOLITE atmospheric correction chain allows simple and fast processing (no external measurements are required) of Landsat 8-OLI images for marine and inland water applications. A fixed $\varepsilon$ was computed here using the data before sun glint correction. The OLI dataset was processed with ACOLITE using the SWIR processing. 


\subsection{Detection of the Location of the Subtidal Part of Mud Banks}

Based on the migration processes and on the satellite data used, an empirically-based method, was developed. Due to the scarcity of in situ measurements on both the temporal and spatial scales, the field detection of mud banks extension and the coupling between physical forcing and mud bank SPM-related dynamics is still poorly constrained. In this context, and based on the current knowledge on mud banks migration processes, an empirical method was developed in order to exploit the information provided by recent high-spatial-resolution sensors such as OLI. The method is based on recurrence values of SPM as follows:

(1) Seasonal SPM maps: as the migration of mud banks is affected by the combined importance of waves, currents, shoreline orientation, and the dynamics of tidal areas [34], and due to well-marked seasonal variations existing in French Guiana, a seasonal distinction of the SPM maps obtained from Landsat 8-OLI scenes was carried out. The rainy season, which lasts from late December to July, is characterised by the strongest winds in the year, which occur from January to April [5], and maximum wave conditions coinciding with the period of intense trade winds [35-37], in contrast to the dry season. Based on these seasonal variations, the SPM maps were classified in a total of nine seasonal time periods along the OLI archive from April 2013 (five dry seasons and four rainy seasons).

(2) Mask of the intertidal part of mud banks using the 65th percentile: SPM concentrations in the nearshore area are always higher than those of the 20-km offshore for the rainy and the dry season, in agreement with previous studies [22]. This higher concentration of SPM in the near coastal zone complicates the identification of the mud bank subtidal footprint. Under certain forcing conditions, the plume (Figure 1b), which represents the SPM resuspended from the subtidal part of the mud bank which is then diversely advected in the surface water masses, can be used as a proxy for its detection and has SPM concentrations that are much lower than those of the intertidal part (Figure 1b,c). Masking the intertidal part of the mud bank makes it possible to distinguish between the plume and the zone outside of the mud bank. Therefore, the higher SPM values were masked using the 65th percentile for each individual OLI scene composing each of the 9 seasonal subsets in order to detect the footprint of the subtidal part.

$$
\text { intertidal mask : SPM values }>\text { percentile } 65=\text { Nan }
$$

(3) Normalisation of the SPM results in the area of study: in order to have a common scale, the SPM results obtained for each OLI map were normalised dividing them by the value corresponding to the 95th percentile (estimated also for each OLI map composing the different seasonal subset). Once the SPM values are normalised, it is necessary to define the SPM concentration threshold for each mud bank area of each map that will delimit the value, after which the pixels will be classified as representing the subtidal part.

$$
\mathrm{SPM}=\frac{\mathrm{SPM}}{\text { percentile } 95}
$$

(4) Definition of the SPM threshold: this threshold value represents the higher values of SPM of each mud bank area once the intertidal part is masked, which corresponds to the footprint of the subtidal zone. The intersection point of (1) a histogram and (b) a cumulative function of the SPM values of each mud bank area of each OLI map is used as a specific threshold value for each mud bank within each OLI image:

$$
\mathrm{T}=\mathrm{SPM} \text { histogram } \cap \mathrm{SPMCF}
$$


where SPM CF is the cumulative function of SPM values, $\cap$ is the intersection between the two curves that define the bin edges and the counts of the histogram (here defined using 100 bins) and the $\mathrm{CF}$, and $\mathrm{T}$ is the threshold value of the zone under study for each OLI map of a defined seasonal subset. All pixels with a SPM value higher than the point defined will be classified as "plume" (giving them a value of 1$)$ or "not plume" ( 0 value). This procedure is repeated for all the SPM maps of the season under study, and a recurrence map is created after the addition of the score given to each map of the total number of scenes of the season.

$$
\begin{gathered}
\text { SPM }>\text { threshold } \rightarrow 1 \text { value : "plume" } \\
\text { SPM }<\text { threshold } \rightarrow 0 \text { value : "not plume" }
\end{gathered}
$$

(5) Normalisation and construction of the final map: the recurrence map is normalised using the maximum for each season:

$$
\text { Recurrence map }=\frac{\text { Recurrence map }}{\max (\text { recurrence map })}
$$

(6) Classification of the final map: based on an empirical approach, the values of the final map (from 0 to 1 ) are classified as "plume" when they are higher than 0.5 , as "migration area" when they are between 0.3 and 0.5 , and as "no bank" if they are lower than 0.3 .

\subsection{SPM Inversion Algorithm}

The semi-analytical algorithm for the retrieval of SPM developed by Han et al. [27] was chosen, as it covers about four orders of magnitude in terms of SPM (from clear to very turbid waters including samples from French Guiana), and was developed for several sensors.

It is based on the consideration of two distinct algorithms according to turbidity levels of the water masses. To prevent any irregularity between the two different algorithms in terms of the spatial patterns of the SPM distribution, a smoothing procedure is applied to the intermediary regions between medium and high turbidity situations. The smoothing method adopted consists of defining a weighting function of the low-medium and high SPM algorithms. The definition of two different weights, one for low SPM conditions $\left(\mathrm{W}_{\mathrm{L}}\right)$, and the other one $\left(\mathrm{W}_{\mathrm{H}}\right)$ for high SPM conditions, was done as follows [27]:

$$
\begin{gathered}
\mathrm{W}_{\mathrm{L}}=\left\{\begin{array}{c}
1, \text { if } \mathrm{R}_{\mathrm{rs}}(655) \leq 0.03 \mathrm{sr}^{-1} \\
0, \text { if } \mathrm{R}_{\mathrm{rs}}(655) \geq 0.045 \mathrm{sr}^{-1}
\end{array}\right. \\
\mathrm{W}_{\mathrm{H}}=\left\{\begin{array}{c}
\log _{10}(0.045)-\log _{10}\left[\mathrm{R}_{\mathrm{rs}}(655)\right], \text { otherwise } \\
0, \text { if } \mathrm{R}_{\mathrm{rs}}(655) \leq 0.03 \mathrm{sr}^{-1} \\
1, \text { if } \mathrm{R}_{\mathrm{rs}}(655) \geq 0.045 \mathrm{sr}^{-1} \\
\log _{10}\left[\mathrm{R}_{\mathrm{rs}}(655)\right]-\log _{10}(0.03), \text { otherwise }
\end{array}\right.
\end{gathered}
$$

The weighted SPM is then computed as:

$$
\mathrm{SPM}=\frac{\mathrm{W}_{\mathrm{L}} \cdot \mathrm{SPM}_{\mathrm{L}}+\mathrm{W}_{\mathrm{H}} \cdot \mathrm{SPM}_{\mathrm{H}}}{\mathrm{W}_{\mathrm{L}}+\mathrm{W}_{\mathrm{H}}}
$$

where $\mathrm{SPM}_{\mathrm{L}}$ and $\mathrm{SPM}_{\mathrm{H}}$ are estimated as follows:

$$
\begin{aligned}
& \operatorname{SPM}_{L}\left(<100 \frac{\mathrm{g}}{\mathrm{m}^{3}}\right)=\frac{\mathrm{A}_{\mathrm{L}} \rho_{\mathrm{W}}(655)}{\left(1-\frac{\rho_{\mathrm{w}}(655)}{\mathrm{C}_{\mathrm{L}}}\right)} \\
& \operatorname{SPM}_{\mathrm{H}}\left(\geq 100 \frac{\mathrm{g}}{\mathrm{m}^{3}}\right)=\frac{\mathrm{A}_{\mathrm{H}} \rho_{\mathrm{w}}(655)}{\left(1-\frac{\rho_{\mathrm{w}}(655)}{C_{\mathrm{H}}}\right)}
\end{aligned}
$$


where $\rho_{\mathrm{W}}(655)$ is the water leaving reflectance at $655 \mathrm{~nm}, \mathrm{~A}_{\mathrm{L}}$ is equal to $346.353 \mathrm{~g} / \mathrm{m}^{3}, \mathrm{C}_{\mathrm{L}}$ is equal to $0.5, A_{H}$ is equal to $1221.39 \mathrm{~g} / \mathrm{m}^{3}$, and $C_{H}$ is equal to 0.3329 for the Landsat 8 satellite.

\subsection{Wave Damping Detection Using the Landsat 8-OLI Panchromatic Band}

Wave-damping limit was used to assess the performance of the method developed for detecting the subtidal part of French Guianese mud banks. Wave-damping limit is an indicator of the presence of fluid mud (10-300 g/L) [9], generally observed in the subtidal part of mud banks.

Wave damping limits were estimated using the Landsat 8-OLI panchromatic band (band 8) due to its higher spatial resolution $(15 \mathrm{~m})$. As a first step, a filter to sharpen the TIF file is applied. The image features, such as the wave crests, are enhanced using the standard deviation of the Gaussian low-pass filter to control the size of the region around the edge pixels affected by sharpening. In order to better detect the edges of the image, a strengthening of the sharpening effect is applied to increase the contrast of the sharpened pixels. To avoid sharpening noise, a threshold is given for the minimum contrast required for a pixel to be considered an edge pixel. This allows sharpening in relatively smooth regions of the image.

A Laplacian of Gaussian filter is created with a size of $5 \times 5$ and a standard deviation of 0.45 . The filter is applied to the sharpened image, allowing the detection of wave damping due to the presence of the subtidal part of the mud banks. The wave damping limits were measured manually using SeaDAS 7.4 (NASA Official-https:/ / seadas.gsfc.nasa.gov/) software for each season (dry and rainy) of each year since 2013.

\section{Results and Discussion}

\subsection{Application of the Developed Methodology to Detect the Subtidal Part of Mud Banks}

The development of a new generation of satellite data for ocean colour extends the available information on different spatial and temporal scales. The spatial resolution of this new satellite generation (30-15 $\mathrm{m}$ for OLI sensor), together with the impossibility of medium-resolution sensors to capture the most ultra-nearshore marine domain due to the presence of clouds, bright pixels, and adjacency effects [38], make it possible to have improved insights into oceanographic processes (Figure 1). In order to better quantify these oceanographic processes, and as already shown by previous studies $[22,30,39,40]$, SPM estimates are a marker of surface currents, and enable different dynamics to be investigated, such as those of French Guiana mud banks and their impacts on these coastal waters. The application of Han algorithm to high- (Landsat 8-OLI) resolution images (Figure 1b,c) illustrates the SPM patterns at the most ultra-nearshore marine domain, as expected, for Landsat 8-OLI images (Figure $1 \mathrm{~b}, \mathrm{c}$ ).

Nevertheless, the latter higher spatial resolution is potentially limited by the temporal resolution (16 days for Landsat 8-OLI) when compared to medium-resolution data (daily data). The SPM patterns estimated after the two Landsat 8-OLI scenes (Figure $1 \mathrm{~b}, \mathrm{c}$ ) show great spatial variability, even though the time elapsed is one month. Figure $1 \mathrm{~b}$ shows higher SPM concentration values in the nearshore waters, $\sim 190 \mathrm{mg} / \mathrm{l}$, corresponding to the intertidal part of the mud bank, while the plume is characterized by low values of SPM, between 40 and $60 \mathrm{mg} / \mathrm{L}$. Conversely, Figure 1c is characterized by a mean value over the plume area of $115 \mathrm{mg} / \mathrm{l}$ and lower concentrations in the intertidal part than for the situation depicted from the Figure $1 \mathrm{~b}, \sim 135 \mathrm{mg} / \mathrm{L}$. These changing patterns are related to the different ocean dynamics (tide, waves, wind, French Guiana current, etc.) affecting SPM distribution, as it has been shown that, for instance, varying tidal conditions induce spatial modulation in the water SPM content [22]. Such variability between consecutive images, together with the number of images per month (a maximum of 2) and the time series length for these sensors (since April 2013 for Landsat 8-OLI), makes it complicated to apply the usual analysis of medium- resolution data (such as trend analysis for example, Vantrepotte et al. [20]) to this kind of remote sensing data. 
In order to solve the temporal resolution problem, the method was applied to the maps corresponding to the different seasons and to the mud bank located in front of Cayenne Island (Figure 1a,b). The location of the footprint of the mud bank for the rainy season of 2016 and the dry season of 2017 is shown in Figure 2. This method based on recurring values makes it possible to capture the changes in the optical characteristics of the coastal waters and their SPM content due to the presence of mud banks, and therefore, to capture the footprint of the subtidal part. Due the erosion and fluidization of the back of the bank (Figure 1b), the SPM values at this part will be higher than at the front of the bank (Figure 1b), misrepresenting the position of the footprint in this area. It is possible to avoid this situation by identifying the intertidal part (Figure 1b) of the bank using the mask step of the method described above. The contour of the footprint at the back of the bank is defined by taking into account the position of this part. The leading edge and the extension of the footprint, as well as the intertidal part, can easily be identified through this method (Figure 2a,b, black dashed lines), the shape of the subtidal part being an approximation defined by taking into account the three different features, and the results of the area classified as the "migration" area (Figure 2a,b, black line).

a)

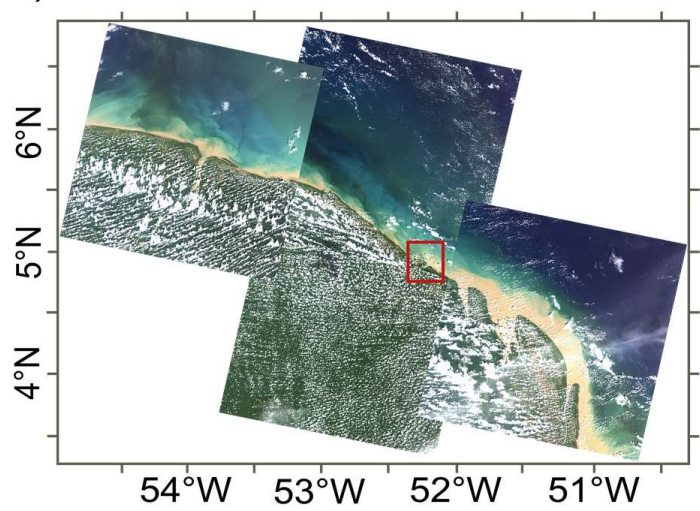

c)

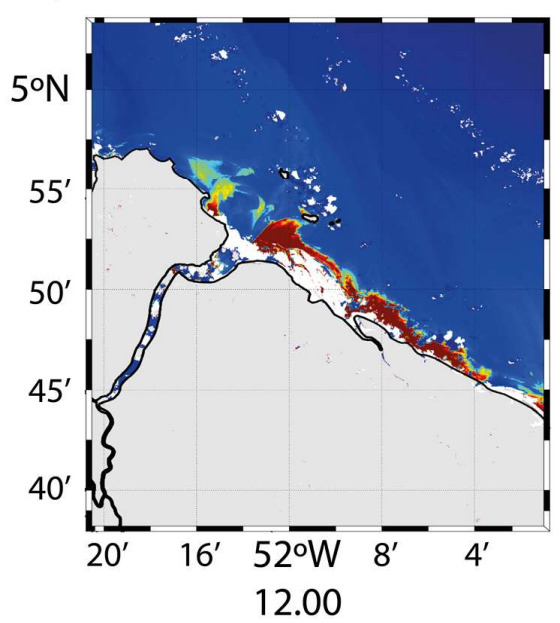

b)

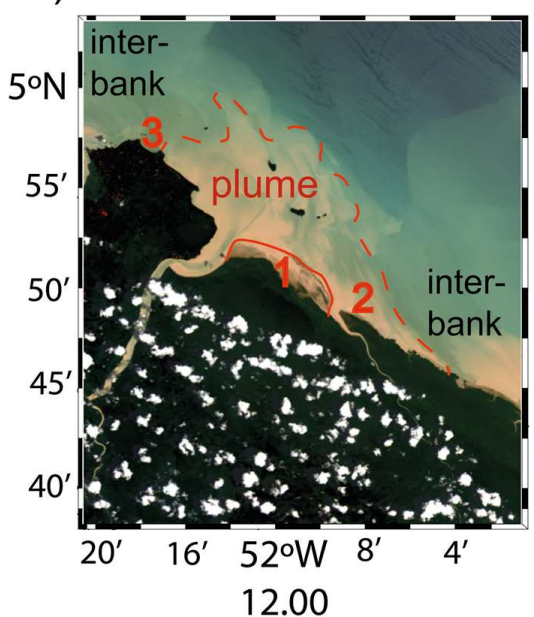

12.00

d)

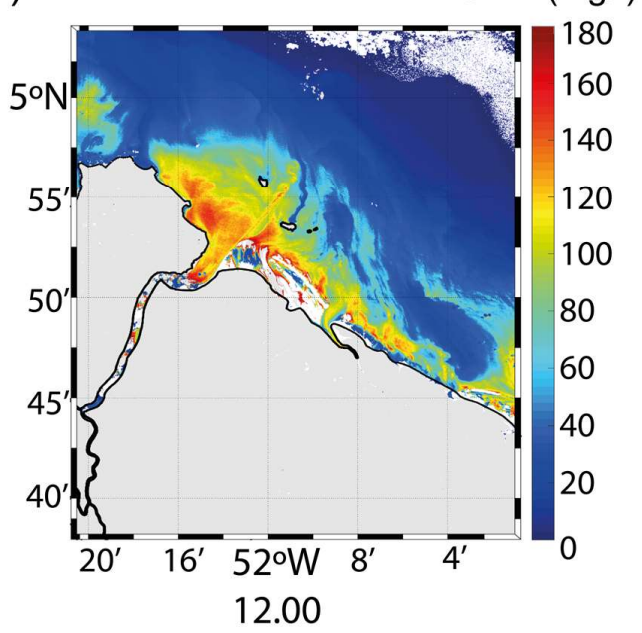

Figure 1. (a) Landsat 8 scenes covering French Guiana's coast. (b) Mud bank located in front of the Cayenne Island, where (1) corresponds to the intertidal part, (2) to the back of the bank, and (3) to the front of the bank and the plume is delimited by the red line (approximate definition). (c) SPM values for the Landsat 8-OLI image for 29 July 2015. (d) SPM values for the Landsat 8-OLI image for 30 August 2015. 
As a result of the different environmental dynamics that play a role in SPM remobilisation between the two seasons, detection of the footprint is limited. SPM remobilisation at the back of the bank is stronger during the rainy season (Figure 2a), as is the flow rate of the Mahury River, which hampers the definition of the contour of the subtidal part. During the rainy season, the river plume has a lower SPM load; therefore, the definition of the leading edge of the mud bank can be affected in the area closest to the coast west of the estuary, which corresponds to the natural channel of the river. Wave conditions during the dry season can also hamper the definition of the subtidal part; for example, for the year 2016, the remobilisation of SPM was lower than for the other years, corresponding to the period with the lowest wave height.

This method is also limited by the number of images available for each season. In the case of the rainy season, the number of maps is restricted due to a significant presence of clouds in the area. For example, for the rainy season of 2014, only two maps are available, making it impossible to estimate the location of the footprint of the mud bank.

Since the wave radian frequency was observed to remain nearly constant up to a depth of $5 \mathrm{~m}$ [9], the $5 \mathrm{~m}$ depth contour is also drawn in Figure 2 (red line). As the method is based on recurring values for different dynamics, the bathymetry value corresponds to this water depth. It seems to be an important value for wave action and SPM remobilisation, as the footprint of the mud banks crosses this line on very few occasions (only during the rainy seasons of 2015 and 2016). This limits the detection of the subtidal part if the bathymetry values are higher than $5 \mathrm{~m}$.

a)

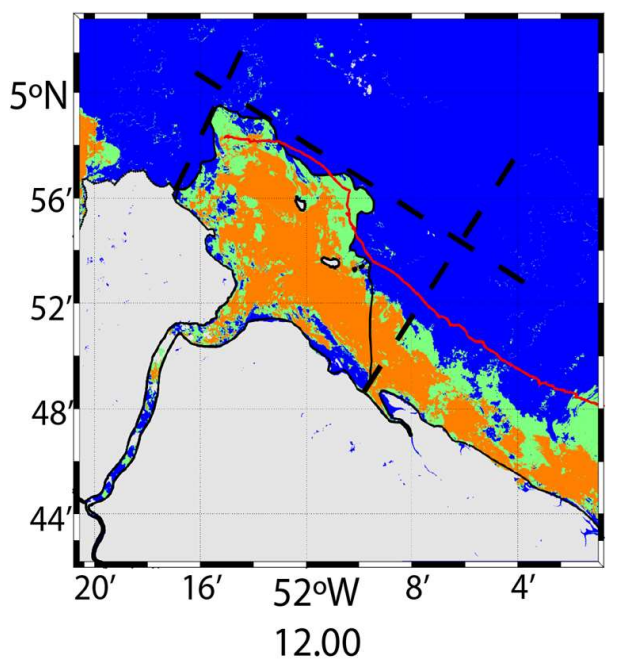

b)

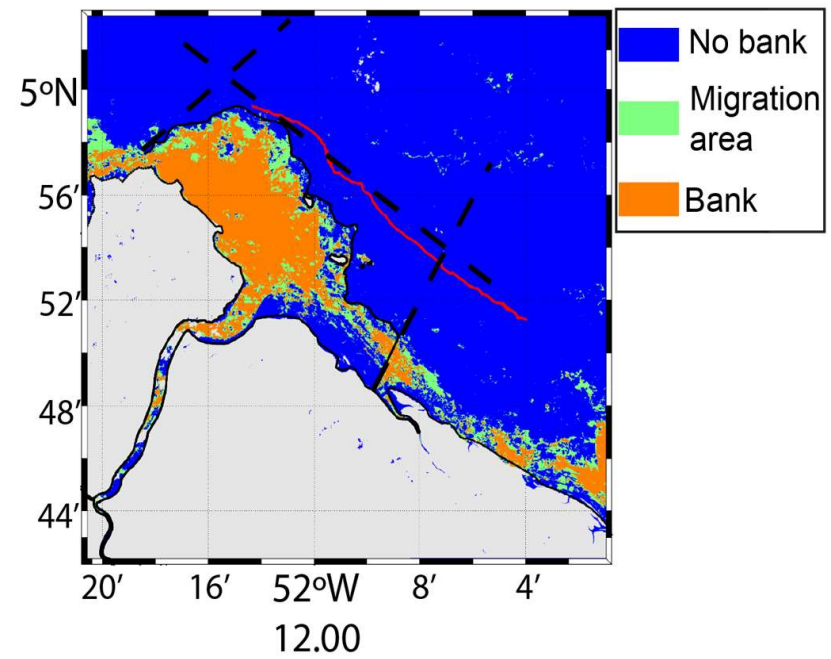

Figure 2. Location of the footprint of the subtidal mud bank estimated using SPM values (a) for the rainy season of 2016 and (b) for the dry season of 2017. The red line corresponds to the $5 \mathrm{~m}$ depth contour and the dashed lines correspond to the leading edge, the back, and the extension of the bank. The black line corresponds to the approximate line that represents the final location used within the framework of this study.

\subsection{Comparison between the SPM and the Wave Damping Based Approaches for Delimiting Mud Banks} Subtidal Extension

As demonstrated by previous studies and for other muddy shorefaces [11,12,41,42], the energy-damping effect of mud on wave height is also observed on the coast of French Guiana (Figure 3). Figure 3b shows the wave height attenuation inside the mud bank area (S1), with a reduction by a factor of 6 when compared to the inter-bank zone (S2), which corresponds to a dissipation rate of $83 \%$, close to the dissipation rates of the Suriname coast $[11,43]$. The wave-damping limit detected between the inter-bank and the bank area over the seismic profile (Figure 3a,c) corresponds to the area of the subtidal part of the mud bank with a more pronounced slope, which indicates the end 
of this area. This damping limit matches the limit detected when applying the method described in Section 2.5 to the panchromatic band of the Landsat 8-OLI scene on the closest date to that of the in situ measurements. The method used allows satisfactory detection of wave damping, as the strong reduction of wave height between the inter-bank and the bank area is well observed. Therefore, and as expected, the wave-damping limit is another possible method for detecting the location of the subtidal part of mud banks (Figure 3).
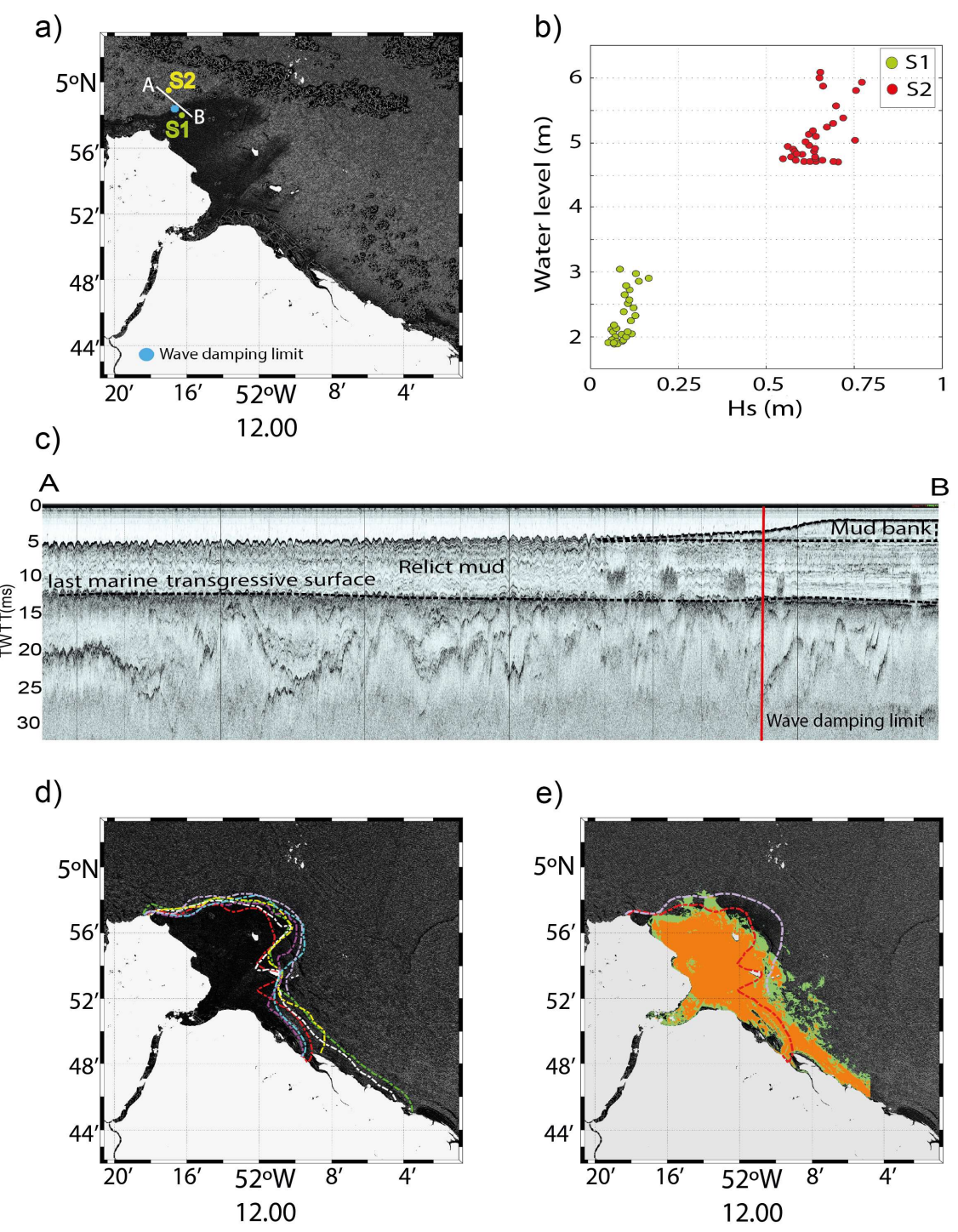

Figure 3. Wave damping over the mud bank located in front of Cayenne Island. (a) Wave damping over the bank for November 2017. (b) Wave height (Hs) in the mud bank area (S1 in Figure 3a) and in the interbank area (S2 in Figure 3a). (c) Identification of the wave-damping limit over the seismic profile (A to B in Figure 3a) for November 2017. (d) Wave detection method using the panchromatic band of Landsat 8 for the maps corresponding to the dry season of 2015. The different coloured lines correspond to the wave damping limits detected for each OLI map of the dry season of 2015. (e) Comparison of mud bank position detection using SPM values and bank position estimated using the extreme values (for the first and the last OLI map of the season) of wave damping for the dry season of 2015.

Wave damping over muddy beds is characterised by a sequence of events [12] that depend on the wave climate and the rheological properties of the mud. Detection of the wave-damping limit will thus be conditioned by these same factors. Figure $3 \mathrm{~d}$ shows the variability of this limit between the seven scenes that correspond to the dry season of 2015 (scenes used to detect the subtidal footprint 
for the same period via the SPM method), pointing out the difficulty of detecting the subtidal region with accuracy for this method as well. This inconstancy is more pronounced at the back of the bank (with a 11.21-km-length maximum difference between images and a $2.381 \mathrm{~km}$ minimum difference) than at the leading edge (only $1.15 \mathrm{~km}$ maximum difference). The extension of the subtidal part also shows a variability of $2.9 \mathrm{~km}$ between the different conditions and maps of 2015. The delimitation of the extension is conditioned by the $5 \mathrm{~m}$ water depth, as are the results using the SPM values, since wave height attenuation is rarely detected beyond that isobath value. Winterwerp et al. [12] indicate that wave height suffers a relative reduction of up to $50 \%$ at water depths of about $5 \mathrm{~m}$ when taking into account wave damping by fluid mud, as observed with the in situ measurements taken within the framework of this study.

The comparison of the wave-damping limits and the limit estimated via the SPM method for the dry season of 2015 (Figure 3e) shows the appropriate delimitation of the subtidal area by the latter method, since it takes into account the fluctuation of this zone, which is influenced by different ocean dynamics and the migration of the mud bank, represented by the green colour (classified as a migration area).

The comparison of both methods for the different seasons over the five years is further depicted in Figure 4. Because of the inter-seasonal variability of the wave-damping limit method, the scenes corresponding to the lowest tide (when available) of the different seasons are used to define the wave-damping limit. We further acknowledge that beside the apparent consistency of the results provided by these two different approaches, which are based on different underlying physical processes, in situ data are still needed to further validate these satellite based estimates. On the regional scale, additional in situ information is, for instance, specifically needed in order to better understand the processes driving the dynamics of the surface mud banks related SPM distribution.

During the dry season and for the five years of the study, both methods provide a similar location of the subtidal area of the mud bank. At the leading edge of the bank, the distance between the two lines is in the order of $\sim 1 \mathrm{~km}$ as the mean maximum value. Due to the influence of the Mahury River and the location of the natural channel, there is an error in the estimation of this edge of the bank, which is greater for the years 2014 and 2015 nearest to the coast. The discrepancy between the two methods of delimiting the extension of the mud bank is the greatest for the years 2013 and 2017 (mean difference $\sim 3 \mathrm{~km}$ ), and the slightest for 2014 and 2015 (mean difference $\sim 0.5 \mathrm{~km}$ ). As observed in Figure 3d, the delimitation of the back of the bank presents a higher variability when using the wave damping method. This higher variability can explain the mean difference between the two methods ( $3.11 \mathrm{~km} \pm 1.9)$, as it is strongly affected by the selection of the lowest tide scene of the period under study.

In the case of the rainy season, estimation of the footprint of the subtidal zone by the SPM method is heavily affected by the strong dynamics that exist at that time of year. These dynamics hamper the assessment at the front of the bank, with a mean delimitation line $1.8 \mathrm{~km}$ northwest of that obtained with wave damping. This is due to the limited number of available maps during the season, but also to stronger advection due to strong dynamics than during the dry season. The extension at the back of the bank is estimated with a difference between the two methods of $4.014 \mathrm{~km} \pm 3.31$ and $1.6 \mathrm{~km} \pm 0.83$ for the extension of the bank.

Both methods provide similar results, especially during the dry season, but they also present similar limitations. The ocean dynamics existing at the moment of the satellite measurement determine their performance, especially during the rainy season. Cloud coverage is also a limitation, especially during the rainy season. The combination of the different existing hydro-meteo dynamics, such as tide, freshwater discharge, stratification, wind and waves, together with the limited number of available data due to cloud coverage, can hamper the detection of the footprint. In the case of the SPM based method, a limited temporal coverage ( $<5$ OLI maps), together with high dynamics (i.e., strong advection) over a defined season, can affect the detection of the mud banks. Conversely, tide and wave energy represent major forcing parameters when aiming to detect mud bank positions using 
wave-damping information. In such a case, mud bank positioning can contain large uncertainties, reaching, for instance, up to $11.21 \mathrm{~km}$ at the back of the bank (Figure 3d). The $5 \mathrm{~m}$ water depth has proven to be an important isobath, as not only the extension of the plume of the subtidal part, but the wave-damping limit as well, are conditioned by it, preventing the detection of the footprint beyond that isobath under certain oceanic conditions (e.g., low energetic conditions). In French Guiana, the $5 \mathrm{~m}$ depth limit seems indeed to provide a good estimate of the limit of wave action, which causes the formation of a fluid mud layer causing wave damping and high SPM resuspension. The advantage of using the information provided by the new generation of satellite data for ocean colour is, therefore, clear, providing better insights into ocean processes such as detection of the subtidal part of mud banks; nevertheless, data processing becomes a challenging task as a consequence of the amount of information available on different spatial and temporal scales [44]. In this context, and due to the similar performance and limitations of both methods, the SPM-based method seems more appropriate, as its adaptation to an automatic procedure in order to ensure continuous monitoring of the mud bank system appears to be more easily achievable.

a)

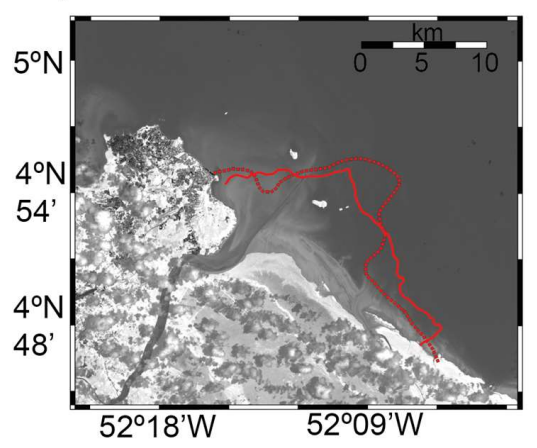

c)

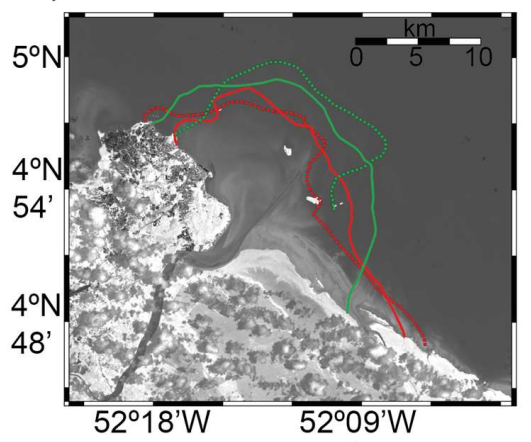

b)

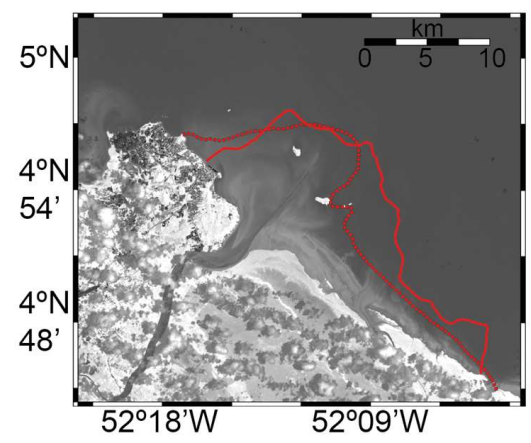

d)

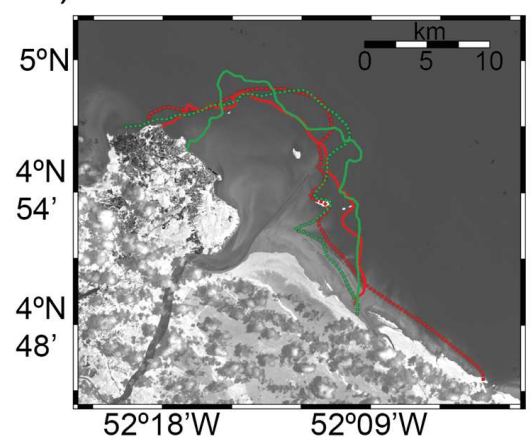

e)

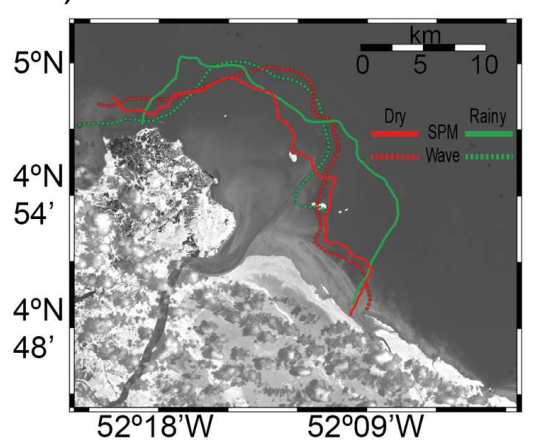

Figure 4. Migration of the mud bank in front of Cayenne Island. Estimation of the footprint of the subtidal part obtained with the SPM values method and the wave damping delimitation method (solid and dashed lines, respectively) for the dry and rainy season (red and blue, respectively). The entire Landsat 8-OLI period is covered (from 2013 to 2017 (a-e)). 


\subsection{Mapping Mud Banks along the French Guianese Coastal}

The application of the SPM method within French Guianese coastal waters reveals the location of the five mud banks present on this coast for each year (from 2013 to 2017). As the differences in the location of the mud bank footprint by the wave damping and SPM methods are much greater for the rainy season, as shown in the previous section, the limits estimated during the dry season are used in order to locate these structures. From east to west, the observed mud banks in French Guiana are as follows: (1) Cayenne mud bank, (2) Kourou mud bank, (3) Sinnamary mud bank, (4) Iracoubo mud bank, and (5) Mana mud bank. The arrival of a new mud bank to the east of the Cayenne mud bank has been observed, as the method developed has made it possible to detect the intertidal part of the mud bank on the western side of the Approuague River estuary (mud bank not shown) (Figure 5).
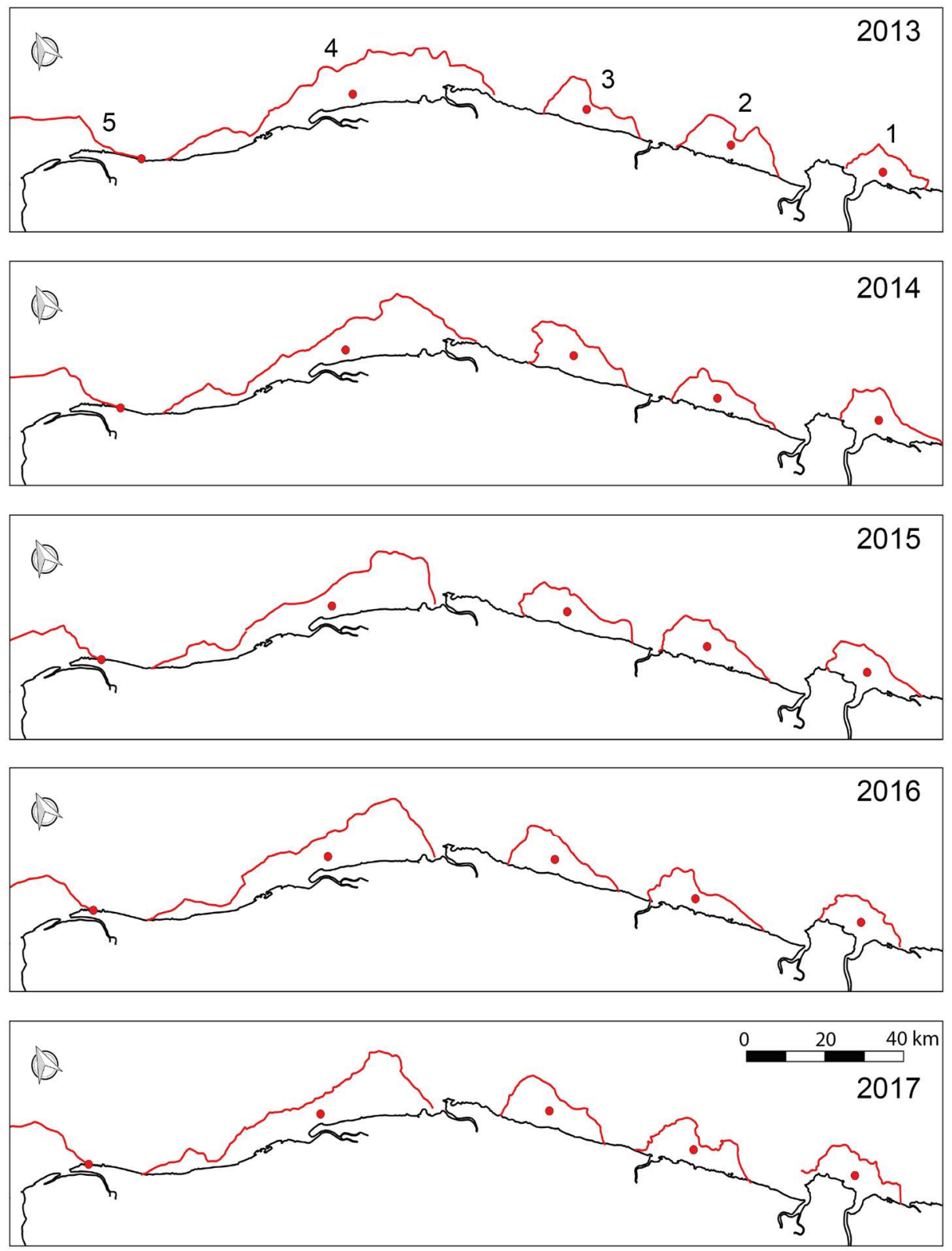

Figure 5. Location and migration of existing mud banks on the French Guianese coastal between the dry seasons of 2013 and 2017. The red line corresponds to the footprint delimitation using the SPM values method, and the red circle corresponds to the barycentre of each mud bank for each year. 
Even though high-resolution sensors are limited by their temporal resolution when compared to medium-resolution satellite data, this study shows for the first time the potential of the Landsat 8-OLI sensor to locate the subtidal part of the entire mud bank system of French Guiana using the method developed. Several studies have proved the potential of satellite data to characterise and monitor mud banks, using either medium-resolution [20] or high-resolution sensors [14,22], but they focused on only one or two of the mud banks in French Guiana's system. Detection of this subtidal area makes it possible to acquire better knowledge on these coastal features, as it enables their progression and shape to be estimated.

The location of the footprint allows the mud bank migration rate for all the mud banks present in French Guiana, which is the subject of many studies [8,14,20], to be estimated, and takes into account for the first time the influence of the shape of the subtidal part. Different methods have been used in order to estimate the velocity of these coastal structures, the main limitation being the impossibility of estimating the alongshore and cross-shore mudflat extension $[8,14]$. In this study, this limitation is resolved and, as has already been done in previous studies [20], the migration rate is estimated according to the barycentre value, here estimated as the barycentre of the shape of the mud bank, compared to the estimation by Vantrepotte et al. [20] based on the migration of the SPM maximum value. The velocities estimated for each mud bank reveal, as outlined by previous studies [14,20], the high spatio-temporal variability of rates of mud bank migration over the period 2013-2017, and a high inter-bank migration speed. The maximum value estimated corresponds to the Sinnamary mud bank (3) between the years 2013 and 2014, with a value of $3.74 \mathrm{~km} / \mathrm{yr}$. At the other extreme, the minimum speed was detected for the Kourou mud bank (2), between 2016 and 2017, with a value of $0.94 \mathrm{~km} / \mathrm{yr}$. The mean speed found was $2.31 \mathrm{~km} / \mathrm{yr} \pm 0.93$, a value that matches the results of previous studies, not only for mud banks located in French Guiana, but also for those in other countries of the system between the Amazon and Orinoco rivers (Suriname: [3,5,35,45]), allowing the performance of the method that uses SPM values to detect the subtidal part of a bank to be validated. The migration rates estimated within the framework of this study, which are slightly higher than those estimated in other works $[14,46]$, follow the detected pattern of an increasing mud bank migration rate $[9,14]$.

Defining the delimitation of the footprint of the subtidal part also highlights the variability in the shape of these entities. Two different bank morphologies were identified. The banks of Cayenne (1), Kourou (2), and Sinnamary (3) have a southeastern side that is steeper than the northwestern side, in contrast to the mud bank of Iracoubo (4), where the northwestern side (leeward) is steeper than the southeastern (windward) side. The surface area of French Guiana's mud banks seems to grow as they migrate towards the northwest; the Sinnamary mud bank is remarkable, with a mean surface area of $526.42 \mathrm{~km}^{2} \pm 37.8$, compared to that of the Cayenne mud bank, with a mean surface area of $151.55 \mathrm{~km}^{2} \pm 16.74$.

Characterisation of the subtidal part of the mud banks allowed not only the migration rates of all the mud banks in the French Guianese coastal system to be estimated, but for the first time, changes in the shape and surface area of these coastal features have been assessed. This new information will enable the influence of the different ocean dynamics on mud banks to be more precisely elucidated. The recent Landsat 8-OLI sensor has not yet provided a significantly long time series to relate this data to the variables that have been used to explain the high inter- and intra-variability of the migration rate, such as the angle of wave incidence on this coast, but also variations in trade wind activity $[5,47]$.

\section{Conclusions}

This study illustrates for the first time the potential of high-resolution sensors, such as Landsat 8-OLI, for characterising the subtidal part of mud banks in the French Guianese coastal waters. This subtidal area is characterised using SPM estimates from ocean colour reflectance measurements. The application of a general algorithm to the very turbid waters of French Guiana makes it possible to identify the footprint of the subtidal area of mud banks, which is associated with a higher remobilisation due to the action of waves and therefore with higher surface SPM values. 
The method, based on recurring SPM values, proved to be a good approach for estimating the footprint of the subtidal part of mud banks. In order to evaluate its performance, a comparison exercise was carried out between the SPM method results and those provided by a different procedure, i.e., the delimitation of the wave damping limit, which is characteristic of muddy coasts and is linked to the subtidal part of mud banks. This comparison carried out for the dry and rainy seasons of the period 2013-2017 highlighted the satisfactory performance of the SPM method during dry seasons. Several limitations were identified for both methods. Ocean dynamics are a limiting factor, especially during the rainy season, as SPM patterns and wave damping limits showed a significant intra-seasonal variability. A water depth of $5 \mathrm{~m}$ also affects the delimitation of the extension of mud banks, as both the footprint of the plume and the wave-damping limit rarely exceed this isobath value. Despite its higher spatial resolution when compared to medium-resolution sensors such as MODIS or VIIRS, the Landsat 8-OLI sensor is limited by its time resolution. For example, during the rainy season, due to the presence of clouds, the number of available images is restricted, and thus constitutes a limitation of the method developed. The recently-launched Sentinel 2 mission (A-23 in June 2015, B-7 in March 2017), with a spatial resolution of $10 \mathrm{~m}$ and a time resolution of 5 days, will allow greater insights into the morphology and dynamics of mud banks to be gained, as its resolution is much higher than that of Landsat 8-OLI. The development of this new generation of satellite data for ocean colour is significantly increasing the amount of information available on different spatial and temporal scales, and satellite big data processing is thus becoming a challenging task [44]. Under these conditions, the application of the wave-damping limit method will become more difficult compared to the implementation of an automatic procedure based on the SPM method for monitoring this mud bank system.

Based on the delimitation of the subtidal part of the mud banks and the estimation of the barycentre of the corresponding surface, the migration rates (mean value of $2.31 \mathrm{~km} / \mathrm{yr}$ ) of the mud banks in French Guiana showed slightly higher values than suggested by earlier studies $[8,14,20]$. In comparison with other methods, the migration rate estimated using the method proposed within the framework of this study takes into account the variability of the shape of the subtidal part for the first time. It was shown that the mud banks existing in the coastal area of French Guiana present two different shapes: those in the coastal area from Cayenne to Iracoubo have a southeastern side that is steeper than the northwestern side, in contrast to those of Iracoubo. The development of this method and the consequent detection of the subtidal part of all French Guiana mud banks for the first time provide an innovative source of information for monitoring their migration and further understand their seasonal and interannual dynamics on a regional scale in response to variations in oceanic conditions. On a broader spatial scale, the potential large applicability of the current method to a variety of mud flat systems is of interest for coastal management applications, and would provide a way to gather better insights into the dynamics of muddy sediments in coastal regions throughout the globe. This study does not address fine-scale physical processes driving SPM dynamics over mud bank areas. This crucial information should be further investigated from dedicated in situ observation and process-based model developments, which still have to be performed specifically over the Amazonian mud banks system.

Author Contributions: Conceptualization, N.A.Z., V.V., N.H and A.G.; Methodology, N.A.Z. and V.V.; Software: N.A.Z., V.V. and E.G.; Validation, N.A.Z and V.V.; Formal Analysis, N.A.Z. and E.G.; Investigation, N.A.Z., V.V., E.G. and A.G.; Resources, V.V., E.G. and A.G.; Data Curation, N.A.Z. and V.V.; Writing-Original Draft Preparation, N.A.Z.; Writing-Review \& Editing, V.V., E.G. and A.G.; Visualization, N.A.Z.; Supervision, V.V., N.H. and A.G.; Project Administration, V.V, N.H. and A.G.; Funding Acquisition, V.V, N.H. and A.G.

Funding: This research was funded by the co-funding of N. Abascal Zorrilla's PhD thesis by the CNES, under the HARDECOT TOSCA project, DEAL Guyane, and Grand Port Maritime de Guyane. Funding was also provided by the European Fund for Regional Development (ERDF) programme OYAMAR and by the French Guiana Office of Water under the EFHEMAR project. The APC was funded by the programme OYAMAR (ERDF).

Acknowledgments: The authors would like to thank Pierrick Pale and Gaëlle Le Maître for processing the wave and seismic data.

Conflicts of Interest: The authors declare no conflict of interest. 


\section{References}

1. Anthony, E.J.; Gardel, A.; Gratiot, N.; Proisy, C.; Allison, M.A.; Dolique, F.; Fromard, F. The Amazon-influenced muddy coast of South America: A review of mud-bank-shoreline interactions. Earth-Sci. Rev. 2010, 103, 99-121. [CrossRef]

2. Martinez, J.M.; Guyot, J.L.; Filizola, N.; Sondag, F. Increase in suspended sediment discharge of the Amazon River assessed by monitoring network and satellite data. Catena 2009, 79, 257-264. [CrossRef]

3. Augustinus, P.G.E.F. The changing shoreline of Surinam (South America). Ph.D. Thesis, University Utrecht, The Netherlands, 1978.

4. Wells, J.T.; Coleman, J.M. Longshore Transport of Mud by Waves: Northeastern Coast of South America; Coastal Studies Institute, Center for Wetland Resources, Louisiana State University: Baton Rouge, LA, USA, 1978.

5. Eisma, D.; Augustinus, P.G.E.F.; Alexander, C. Recent and subrecent changes in the dispersal of amazon mud. Neth. J. Sea Res. 1991, 28, 181-192. [CrossRef]

6. Allison, M.A.; Lee, M.T.; Ogston, A.S.; Aller, R.C. Origin of Amazon mudbanks along the northeastern coast of South America. Mar. Geol. 2000, 163, 241-256. [CrossRef]

7. Warne, A.G.; Meade, R.H.; White, W.A.; Guevara, E.H.; Gibeaut, J.; Smyth, R.C.; Aslan, A.; Tremblay, T. Regional controls on geomorphology, hydrology, and ecosystem integrity in the Orinoco Delta, Venezuela. Geomorphology 2002, 44, 273-307. [CrossRef]

8. Froidefond, J.M.; Pujos, M.; Andre, X. Migration of mud banks and changing coastline in French Guiana. Mar. Geol. 1988, 84, 19-30. [CrossRef]

9. Gratiot, N.; Gardel, A.; Anthony, E.J. Trade-wind waves and mud dynamics on the French Guiana coast, South America: Input from ERA-40 wave data and field investigations. Mar. Geol. 2007, 236, 15-26. [CrossRef]

10. NEDECO. Report on Sea Defence Studies of British Guyana; NEDECO: Hague, The Netherlands, 1972.

11. Wells, J.T.; Kemp, P. Estuarine Cohesive Sediment Dynamics; Mehta, A.J., Ed.; Springer: New York, NY, USA, 1986.

12. Winterwerp, J.C.; de Graaff, R.F.; Groeneweg, J.; Luijendijk, A.P. Modelling of wave damping at Guyana mud coast. Coast. Eng. 2007, 54, 249-261. [CrossRef]

13. Lefebvre, J.P.; Dolique, F.; Gratiot, N. Geomorphic evolution of a coastal mudflat under oceanic influences: An example from the dynamic shoreline of French Guiana. Mar. Geol. 2004, 208, 191-205. [CrossRef]

14. Gardel, A.; Gratiot, N. A Satellite Image-Based Method for Estimating Rates of Mud Bank Migration, French Guiana, South America. J. Coast. Res. 2005, 214, 720-728. [CrossRef]

15. Anthony, E.J.; Dolique, F.; Gardel, A.; Gratiot, N.; Proisy, C.; Polidori, L. Nearshore intertidal topography and topographic-forcing mechanisms of an Amazon-derived mud bank in French Guiana. Cont. Shelf Res. 2008, 28, 813-822. [CrossRef]

16. Anthony, E.J.; Dolique, F. The influence of Amazon-derived mud banks on the morphology of sandy headland-bound beaches in Cayenne, French Guiana: A short- to long-term perspective. Mar. Geol. 2004, 208, 249-264. [CrossRef]

17. Allison, M.A.; Lee, M.T. Sediment exchange between Amazon mudbanks and shore-fringing mangroves in French Guiana. Mar. Geol. 2004, 208, 169-190. [CrossRef]

18. Doxaran, D.; Froidefond, J.M.; Lavender, S.; Castaing, P. Spectral signature of highly turbid waters: Application with SPOT data to quantify suspended particulate matter concentrations. Remote Sens. Environ. 2002, 81, 149-161. [CrossRef]

19. Doxaran, D.; Froidefond, J.M.; Castaing, P.; Babin, M. Dynamics of the turbidity maximum zone in a macrotidal estuary (the Gironde, France): Observations from field and MODIS satellite data. Estuar. Coast. Shelf Sci. 2009, 81, 321-332. [CrossRef]

20. Vantrepotte, V.; Gensac, E.; Loisel, H.; Gardel, A.; Dessailly, D.; Mériaux, X. Satellite assessment of the coupling between in water suspended particulate matter and mud banks dynamics over the French Guiana coastal domain. J. South Am. Earth Sci. 2013, 44, 25-34. [CrossRef]

21. Froidefond, J.M.; Gardel, L.; Guiral, D.; Parra, M.; Ternon, J.F. Spectral remote sensing reflectances of coastal waters in French Guiana under the Amazon influence. Remote Sens. Environ. 2002, 80, 225-232. [CrossRef]

22. Froidefond, J.M.; Lahet, F.; Hu, C.; Doxaran, D.; Guiral, D.; Prost, M.T.; Ternon, J.F. Mudflats and mud suspension observed from satellite data in French Guiana. Mar. Geol. 2004, 208, 153-168. [CrossRef] 
23. Nechad, B.; Ruddick, K.G.; Park, Y. Calibration and validation of a generic multisensor algorithm for mapping of total suspended matter in turbid waters. Remote Sens. Environ. 2010, 114, 854-866. [CrossRef]

24. Doxaran, D. A reflectance band ratio used to estimate suspended matter concentration in sediment-dominant coastal waters concentrations in sediment-dominated coastal waters. Int. J. Remote Sens. 2002. [CrossRef]

25. Doxaran, D.; Froidefond, J.-M.; Castaing, P. Remote-sensing reflectance of turbid sediment-dominated waters Reduction of sediment type variations and changing illumination conditions effects by use of reflectance ratios. Appl. Opt. 2003, 42, 2623. [CrossRef] [PubMed]

26. Doxaran, D. Use of reflectance band ratios to estimate suspended and dissolved matter concentrations in estuarine waters Use of reflectance band ratios to estimate suspended and dissolved. Int. J. Remote Sens. 2005, 26, 1763-1769. [CrossRef]

27. Han, B.; Loisel, H.; Vantrepotte, V.; Mériaux, X.; Bryère, P.; Ouillon, S.; Dessailly, D.; Xing, Q.; Zhu, J. Development of a Semi-Analytical Algorithm for the Retrieval of Suspended Particulate Matter from Remote Sensing over Clear to Very Turbid Waters. Remote Sens. 2016, 8, 211. [CrossRef]

28. Wu, G.; Cui, L.; Liu, L.; Chen, F.; Fei, T.; Liu, Y. Statistical model development and estimation of suspended particulate matter concentrations with Landsat 8 OLI images of Dongting Lake, China. Int. J. Remote Sens. 2015, 36, 343-360. [CrossRef]

29. Liu, H.; Li, Q.; Shi, T.; Hu, S.; Wu, G.; Zhou, Q. Application of Sentinel 2 MSI Images to Retrieve Suspended Particulate Matter Concentrations in Poyang Lake. Remote Sens. 2017, 9, 761. [CrossRef]

30. Vantrepotte, V.; Loisel, H.; Meriaux, X.; Neukermans, G.; Dessailly, D.; Jamet, C.; Gensac, E.; Gardel, A. Seasonal and inter-annual (2002-2010) variability of the suspended particulate matter as retrieved from satellite ocean color sensor over the French Guiana coastal waters. J. Coast. Res. 2011, 64, 1750-1754.

31. Paquier, A.-É; Meulé, S.; Anthony, E.J.; Bernard, G. Sedimentation and erosion patterns in a low shoot-density Zostera noltii meadow in the fetch-limited Berre lagoon, Mediterranean France. J. Coast. Res. 2014, 70, 563-567. [CrossRef]

32. Abascal Zorrilla, N.; Vantrepotte, V.; Dinh Ngoc, D.; Huybrechts, N.; Gardel, A. Automated SWIR based empirical sun glint correction of Landsat 8-OLI data over coastal turbid waters. Opt. Express 2018, in press.

33. Lyzenga, D.R.; Malinas, N.P.; Tanis, F.J. Multispectral bathymetry using a simple physically based algorithm. IEEE Trans. Geosci. Remote Sens. 2006, 44, 2251-2259. [CrossRef]

34. Orseau, S.; Lesourd, S.; Huybrechts, N.; Gardel, A. Hydro-sedimentary processes of a shallow tropical estuary under Amazon influence. The Mahury Estuary, French Guiana. Estuar. Coast. Shelf Sci. 2017, 189, 252-266. [CrossRef]

35. NEDECO. Surinam Transportation Study: Report on Hydraulic Inverstigation; Delft Hydraulics: The Hague, Netherlands, 1968.

36. Meserve, J.M. U.S. Navy Marine Climatic Atlas of the World: Volume I: North Atlantic Ocean; United States Government Printing Office: Washington, DC, USA, 1974.

37. Pujos, M.; Froidefond, J.M. Water masses and suspended matter circulation on the French Guiana continental shelf. Cont. Shelf Res. 1995, 15, 1157-1171. [CrossRef]

38. Santer, R.; Schmechtig, C. Adjacency effects on water surfaces: Primary scattering approximation and sensitivity study. Appl. Opt. 2000, 39, 361-375. [CrossRef] [PubMed]

39. Doxaran, D.; Castaing, P.; Lavender, S.J. Monitoring the maximum turbidity zone and detecting fine-scale turbidity features in the Gironde estuary using high spatial resolution satellite sensor (SPOT HRV, Landsat ETM+) data. Int. J. Remote Sens. 2006, 27, 2303-2321. [CrossRef]

40. Gensac, E.; Martinez, J.-M.; Vantrepotte, V.; Anthony, E. Seasonal and inter-annual dynamics of suspended sediment at the mouth of the Amazon River: The role of continental and oceanic forcing, and implications for coastal geomorphology and mud bank formation. Cont. Shelf Res. 2016, 118, 49-62. [CrossRef]

41. Narayana, A.C.; Jago, C.F.; Manojkumar, P.; Tatavarti, R. Nearshore sediment characteristics and formation of mudbanks along the Kerala coast, southwest India. Estuar. Coast. Shelf Sci. 2008, 78, 341-352. [CrossRef]

42. Jaramillo, S.; Sheremet, A.; Allison, M.A.; Reed, A.H.; Holland, K.T. Wave-mud interactions over the muddy Atchafalaya subaqueous clinoform, Louisiana, United States: Wave-supported sediment transport. J. Geophys. Res. Oceans 2009, 114, 1-18. [CrossRef]

43. Wells, J.T. Dynamics of coastal fluid muds in low-, moderate-, and high-tide-range environments. Can. J. Fish. Aquat. Sci. 1983, 40, s130-s142. [CrossRef] 
44. Ma, Y.; Wu, H.; Wang, L.; Huang, B.; Ranjan, R.; Zomaya, A.; Jie, W. Remote sensing big data computing: Challenges and opportunities. Futur. Gener. Comput. Syst. 2015, 51, 47-60. [CrossRef]

45. Augustinus, P.G.E.F. The geomorphologic development of the coast of Guiana between the Corentyne river and the Essequibo river. In International Geomorphology; Gardiner, V., Ed.; Wiley: New York, NY, USA, 1987; pp. 1281-1292.

46. Anthony, E.J.; Gardel, A.; Proisy, C.; Fromard, F.; Gensac, E.; Peron, C.; Walcker, R.; Lesourd, S. The role of fluvial sediment supply and river-mouth hydrology in the dynamics of the muddy, Amazon-dominated Amapá-Guianas coast, South America: A three-point research agenda. J. South Am. Earth Sci. 2013, 44, 18-24. [CrossRef]

47. Augustinus, P.G.E.F. The influence of the trade winds on the coastal development of the Guianas at various scale levels: A synthesis. Mar. Geol. 2004, 208, 145-151. [CrossRef]

(C) 2018 by the authors. Licensee MDPI, Basel, Switzerland. This article is an open access article distributed under the terms and conditions of the Creative Commons Attribution (CC BY) license (http://creativecommons.org/licenses/by/4.0/). 